\title{
Numerical modeling of elastomeric seismic isolators for determining force-displacement curve from cyclic loading
}

\author{
Majid Saedniya ${ }^{1}$. Sayed Behzad Talaeitaba ${ }^{2}$
}

Received: 12 May 2018 / Accepted: 3 August 2019 / Published online: 13 August 2019

(c) The Author(s) 2019

\begin{abstract}
The ideal performance of seismic isolating systems during the past earthquakes has proved them to be very useful in protecting structures against earthquakes. The cyclic loading experimental tests are an important part in the process of completing the design of the isolators, yet they are very expensive and time consuming. Using the accurate analytical modeling of hysteresis tests and knowing the limitations and the amount of error of the finite elements model and its effect on designing the isolated structure make it possible to reduce the financial and time expenses involved in designing seismic isolators along with experimental tests. In the present study, the cyclic loading of two different isolating systems, namely, the high damping rubber bearing (HDRB) and lead rubber bearing (LRB) have been modeled and analyzed in ABAQUS and the outcomes were compared with the experimental results attained by other researchers. Regarding the fact that the most important and complicated component of the elastomeric isolating system is rubber, it was modeled using various strain energy functions. Other factors affecting the finite elements models of elastomeric isolators were also studied. After comparing the effective stiffness of the experimental sample with the analytical model of HDRB, the Yeoh function had the best performance in determining the effective stiffness of the isolating system with an error of less than 7\%. In studying LRBs, too, three types of bearings with different dimensions and lateral strain values were studied; the polynomial function in shear strain value of $150 \%$ had the best performance in estimating effective stiffness and damping with errors of less than $3 \%$ and $18 \%$, respectively.
\end{abstract}

Keywords Cyclic loading test $\cdot$ High damping rubber bearing $\cdot$ Lead rubber bearing $\cdot$ Finite element analysis $\cdot$ Strain energy function $\cdot$ Analytical modeling

\section{Introduction}

To design an elastomeric isolating system, first the size and characteristics of the isolator such as its stiffness and effective damping are determined based on the type and features of the structure as well as the instructions in related codes and the tables suggested by the manufacturers. Afterwards, the first sample of isolators is produced by the manufacturer. Regarding the importance of proper performance of these bearings, they must undergo some cyclic loading tests so that their force-displacement behavior can be acquired.

Sayed Behzad Talaeitaba talaeetaba@iaukhsh.ac.ir

1 Islamic Azad University of Khomein, Khomein, Iran

2 Islamic Azad University of Khomein, Khomeinishahr Branch of Azad University, P.O. Box: 84175-119, Khomeyni Shahr, Iran
Among the most important factors that should be reported in the results of such tests are (Naeim and Kelly 1999):

- design displacement;

- effective stiffness in the design displacement;

- amount of energy damping in each cycle at the design displacement.

After delivering the accurate values from lab tests, the isolator and the structure's design are modified. These tests, although having lots of significant advantages, are very expensive. Moreover, during the communication cycle between the lab and the designers before reaching acceptable results, a lot of time and money is spent. In the present study, we tried to examine high damping rubber bearings (HDRBs) and lead rubber bearings (LRBs) using the finite element software (ABAQUS) to: 
1. Investigate the possibility of reducing the expenses of manufacturing isolators through modeling the hysteresis cycle tests.

2. Exactly know the effective factors in the resulting error and the contribution of each of them in that.

3. Learn about the performance of seismic isolating systems before running experimental tests.

4. Control the future experimental tests.

5. Have the ability to build some new seismic isolators and model their tests using the results of the present study.

In the past, researchers have used numerical methods as a seismic isolator analysis tool. In all of these researches, the main goal was to obtain precise and inexpensive models for the analysis of isolators by numerical methods (Asl et al. 2014; Ohsaki et al. 2015; Mishra et al. 2013; Talaeitaba et al. 2019).

\section{Finite element modeling}

Modeling the seismic isolators using the finite element software program is generally done in two ways. In the first, the whole isolating part and the structures under and over it are modeled in the form of concentrated mass, spring, and damper, then the whole system behavior is assessed. In the second method, however, only the isolating system is modeled and tests on it were performed (Suhara et al. 1992; Martelli et al. 1992).

\section{Modeling methods of the parts}

At the beginning of the analysis process, each element can generally be modeled in three forms: two-dimensional, three-dimensional, and axisymmetrical. Two-dimensional modeling has a lot of limitations and was popular in the past decades regarding the hardware possibilities of those days (Imbimbo and De Luca 1998). Most cases of modeling now are three-dimensional or axisymmetrical. Forni et al. state that although in axisymmetrical models the solution process takes less time, they will not be very accurate for shear strains of more than $150 \%$ and three-dimensional models are more efficient for horizontal deformations (Talaeitaba et al. 2019).

\section{Introducing materials}

The most important step in modeling an elastomeric isolator is defining the materials especially rubber. In this section, the properties of the materials used in the model are explained.

\section{Steel}

The main role of the steel in rubber isolators is preventing high strains under vertical loads. The best-known materials for modeling are metals. Steel was defined as an elastoplastic material with characteristics presented in Table 1 (Mori et al. 1996; Doudoumis et al. 2005).

\section{Lead}

Lead has a crystal structure which will change as displacement increases. Lead reaches the yield under shear force in relatively low tensions of about $8-10 \mathrm{MPa}$ and shows a stable hysteresis behavior and never reaches fatigue due to the repeated yields under the lateral cyclic dynamic loads (Trevor 2001). Lead is defined as an elastoplastic material according to Table 2 .

\section{Rubber}

The elastomeric materials have an almost linear behavior in small strains; however, their behavior is highly non-linear and elastic in large strains. This non-linear behavior causes the material's parameters including the shear modulus and elasticity modulus to change as the strain increases (Guo and Sluys 2008). The rubber's shear modulus and damping depend on the load size, temperature changes, and the strain history (Charlton et al. 1993).

In the finite element program, materials whose stress-strain curve in large deformations is non-linear and elastic are called hyperelastic materials. Polymers such as rubber are among these (APASmith 2007).

To model these materials, they can be assumed to be isotropic, isothermal, elastic, and incompressible. The effect of loading frequency and time on their behavior is also ignored (Salomon et al. 1999; Venkatesh and Srinivasa Murthy 2012).

Hyperelastic materials are described in terms of "strain energy potential" $(U)$ which defines the strain energy stored in the material per unit of reference volume (volume in the initial configuration) as a function of the strain at that point in the material (APASmith 2007).

Table 1 Steel properties (Imbimbo and De Luca 1998)

\begin{tabular}{ll}
\hline Modulus of elasticity & $210,000 \mathrm{MPa}$ \\
Poisson's ratio & 0.3 \\
Yield stress & $240 \mathrm{MPa}$ \\
\hline
\end{tabular}

Table 2 Lead properties (Doudoumis et al. 2005)

\begin{tabular}{ll}
\hline Modulus of elasticity & $18,000 \mathrm{MPa}$ \\
Poisson's ratio & 0.43 \\
Yield stress & $19.5 \mathrm{MPa}$ \\
\hline
\end{tabular}


These functions have the following characteristics (Garcia et al. 2005):

1. The stress-strain function of the model will not change for frequent loadings.

2. The stress-strain function is fully reversible.

3. The materials are assumed to be completely elastic with no permanent deformation.

There are several forms of strain energy potentials available in Abaqus to model approximately incompressible isotropic elastomers which are listed below. In the presented equations, $I_{1}, I_{2}$, and $I_{3}$ are the deviatoric strain invariants. Strain energy functions are defined by these coefficients. Also, $J^{\mathrm{e}}$ is the elastic volume ratio (APASmith 2007).

i. Mooney-Rivlin form

$U=C_{10}\left(I_{1}-3\right)+C_{01}\left(I_{2}-3\right)+\frac{1}{D_{1}}\left(J^{\mathrm{el}}-1\right)^{2}$,

where $U$ is the strain energy per unit of reference volume. $C_{01}, C_{10}, D_{1}$ are the temperature-dependent material parameters.

ii. Neo-Hookean form

$U=C_{10}\left(I_{1}-3\right)+\frac{1}{D_{1}}\left(J^{\mathrm{el}}-1\right)^{2}$,

where $D_{1}$ and $C_{10}$ are the temperature-dependent material parameters.

iii. Ogden form

$U=\sum_{i=1}^{N} \frac{2 \mu_{i}}{\alpha_{i}^{2}}\left(\lambda_{1}^{\alpha_{i}}+\lambda_{2}^{\alpha_{i}}+\lambda_{3}^{\alpha_{i}}-3\right)+\sum_{i=1}^{N} \frac{1}{D_{i}}\left(J^{\mathrm{el}}-1\right)^{2 i}$,

where $\mu_{i}, \alpha_{i}, D_{i}$ are the temperature-dependent material parameters and $N$ is the material parameter.

iv. Yeoh form

$$
\begin{aligned}
U= & C_{10}\left(I_{1}-3\right)+C_{20}\left(I_{1}-3\right)^{2}+C_{30}\left(I_{1}-3\right)^{3} \\
& +\frac{1}{D_{1}}\left(J^{\mathrm{el}}-1\right)^{2}+\frac{1}{D_{2}}\left(J^{\mathrm{el}}-1\right)^{4}+\frac{1}{D_{3}}\left(J^{\mathrm{el}}-1\right)^{6},
\end{aligned}
$$

where $C_{i 0}$ and $D_{i}$ are the temperature-dependent material parameters.

v. Arruda-Boyce form

$$
\begin{aligned}
U= & \mu\left\{\frac{1}{2}\left(I_{1}-3\right)+\frac{1}{20 \lambda_{m}^{2}}\left(I_{1}^{2}-9\right)+\frac{11}{1050 \lambda_{m}^{4}}\left(I_{1}^{3}-27\right)\right. \\
& \left.+\frac{19}{7000 \lambda_{m}^{6}}\left(I_{1}^{4}-81\right)+\frac{519}{613750 \lambda_{m}^{8}}\left(I_{1}^{5}-243\right)\right\} \\
& +\frac{1}{D}\left(\frac{J^{\mathrm{el} 2}-1}{2}-\ln J^{\mathrm{el}}\right)
\end{aligned}
$$

where $\mu, \lambda_{m}$ and $D$ are the temperature-dependent material parameters. The locking stretch $\lambda_{m}$ can be obtained from the limiting chain stretch $\left(\lambda_{\text {lim }}\right)$, which is the stretch at which the stress starts to increase without any limit (see Fig. 1; Bergstrom 2002). $\lambda_{m}$ is determined according to the Eq. (6).

$\lambda_{m}=\sqrt{\frac{1}{3}\left[\lambda_{\lim }^{2}+\frac{2}{\lambda_{\lim }}\right]}$.

\section{vi. Polynomial form}

$U=\sum_{i+j=1}^{N} C_{i j}\left(I_{1}-3\right)^{i}\left(I_{2}-3\right)^{j}+\sum_{i=1}^{N} \frac{1}{D_{i}}\left(J^{\mathrm{el}}-1\right)^{2 i}$,

where $C_{i j}$ and $D_{i}$ are the temperature-dependent material parameters. $N$ is a material parameter.

vii. Reduced polynomial form

$U=\sum_{i=1}^{N} C_{i 0}\left(I_{1}-3\right)^{i}+\sum_{i=1}^{N} \frac{1}{D_{i}}\left(J^{\mathrm{el}}-1\right)^{2 i}$

viii. van der Waals form

$$
\begin{aligned}
U= & \mu\left\{-\left(\lambda_{m}^{2}-3\right)[\ln (1-\eta)+\eta]-\frac{2}{3} a\left(\frac{I-3}{2}\right)^{\frac{3}{2}}\right\} \\
& +\frac{1}{D}\left(\frac{J^{\mathrm{el} 2}-1}{2}-\ln J^{\mathrm{el}}\right),
\end{aligned}
$$

where

$I=(1-\beta) I_{1}+\beta I_{2}$

$\eta=\sqrt{\frac{I-3}{\lambda_{m}^{2}-3}}$

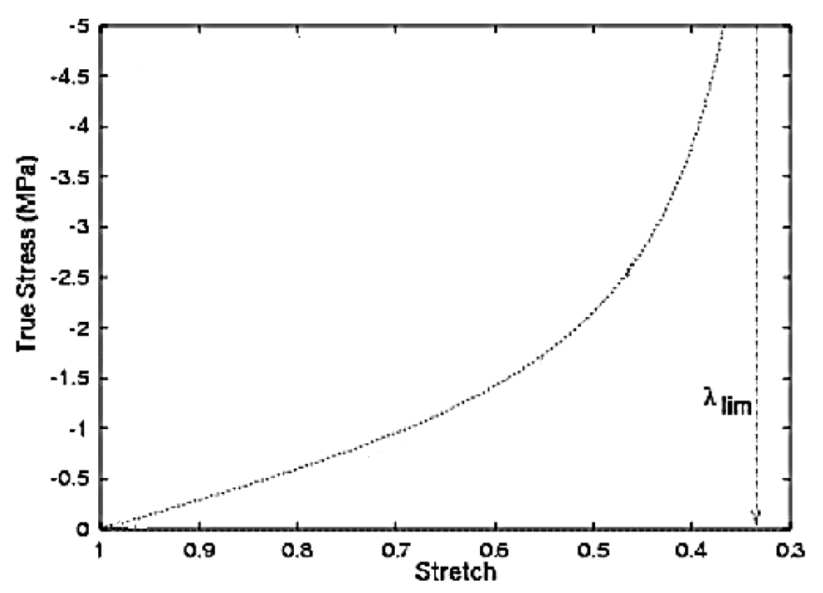

Fig. 1 Determining the limiting chain stretch $\left(\lambda_{\lim }\right)$ (Bergstrom 2002) 
In order for the design predictions to be relevant, it is essential that the materials' properties are determined under test conditions appropriate for the service conditions. Where combinations of test data are supplied to derive model coefficients, these data must be determined at the same temperatures and strain rates (Garcia et al. 2005). These tests specify the force-displacement relation of the material in four different modes of deformation which follow (Charlton et al. 1993):

1. Uniaxial tension and compression test.

2. Equibiaxial tension and compression test

3. Planar shear test (also known as pure shear).

4. Volumetric tension and compression.

All tests must be done on the same material and at the same temperature. The most commonly performed experiments are uniaxial tension, uniaxial compression, and planar tension. After running these tests and determining the strain-stress relation in each of the above modes, the results are fed into the program and the program matches the results with the function; then the adapted curve is exhibited and the required coefficients are determined (APASmith 2007). In other words, for each of the above tests, the test is simulated with ABAQUS software, and then the required parameters of the simulation are extracted.

\section{Modeling the high damping rubber bearing (HDRB)}

The high damping rubber bearing under study is selected from the research done by Yoo et al. in the Korea Atomic Energy Research Institute (Doudoumis et al. 2005; Yoo et al. 2002).

\section{Geometry}

The model is three-dimensional with the following attributes presented in Table 3.

Table 3 Geometric features of the HDRB (Doudoumis et al. 2005)

\begin{tabular}{ll}
\hline Diameter of isolator $(\mathrm{mm})$ & 125 \\
Thickness of rubber sheet $(\mathrm{mm})$ & 2.5 \\
Number of rubber sheets & 12 \\
Total rubber thickness $(\mathrm{mm})$ & 30 \\
Initial shape factor & 12 \\
Thickness of inner steel plates $(\mathrm{mm})$ & 1 \\
Number of steel plates & 11 \\
Thickness of top and bottom loading plates $(\mathrm{mm})$ & 5
\end{tabular}

\section{Defining materials}

The high damping rubber bearing consists of two materials: rubber and steel. Steel is defined as an elastoplastic material with the properties given in Table 1 . To model the rubber, uniaxial, biaxial, and planar shear tests were carried out (Yoo et al. 2002; Busfield and Muhr 2003; Tun Abdul Razak Research Centre 2002; Bradley et al. 2001) whose results are presented in Figs. 2, 3 and 4. The initial shear modulus for rubber is $0.4 \mathrm{MPa}$.

Regarding rubber tests' results and by matching curves with each of the strain energy functions, the coefficients for each function were determined as Table 4 .

Afterwards to specify the amount of error in each model, the value of shear modulus for each function was compared with its experimental value.

As seen in Table 5, the best estimation of the initial shear modulus was done by van der Waals and Yeoh functions. After that comes Arruda-Boyce and polynomial $(N=2)$, Ogden $(N=3)$, neo-Hookean and Mooney-Rivlin functions in order of estimation accuracy. Other than the functions of

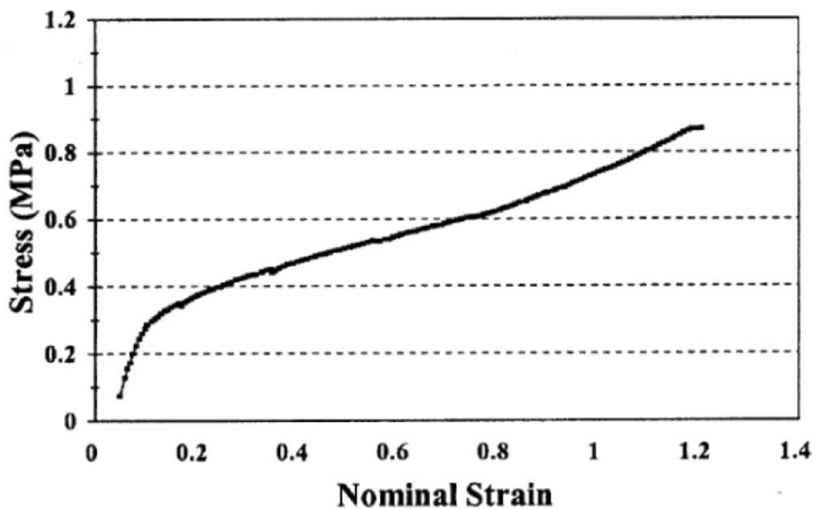

Fig. 2 Rubber's uniaxial test (Yoo et al. 2002; Busfield and Muhr 2003; Tun Abdul Razak Research Centre 2002; Bradley et al. 2001)

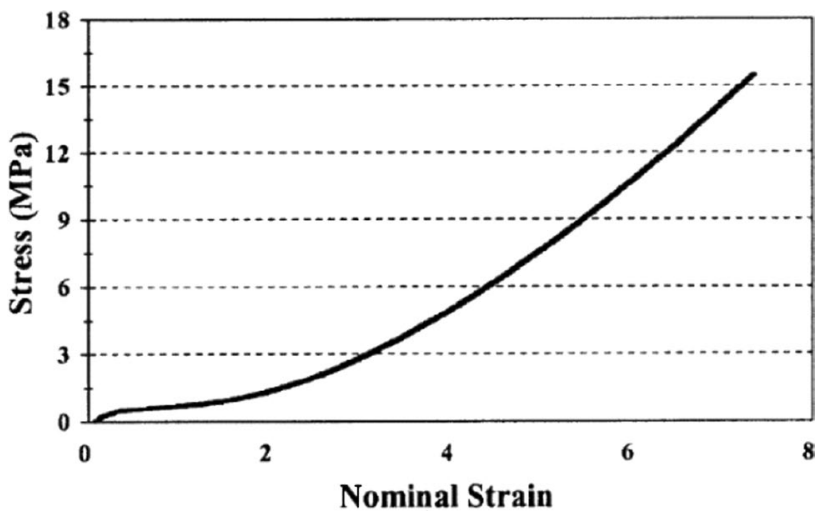

Fig. 3 Rubber's biaxial test (Yoo et al. 2002; Busfield and Muhr 2003; Tun Abdul Razak Research Centre 2002; Bradley et al. 2001) 


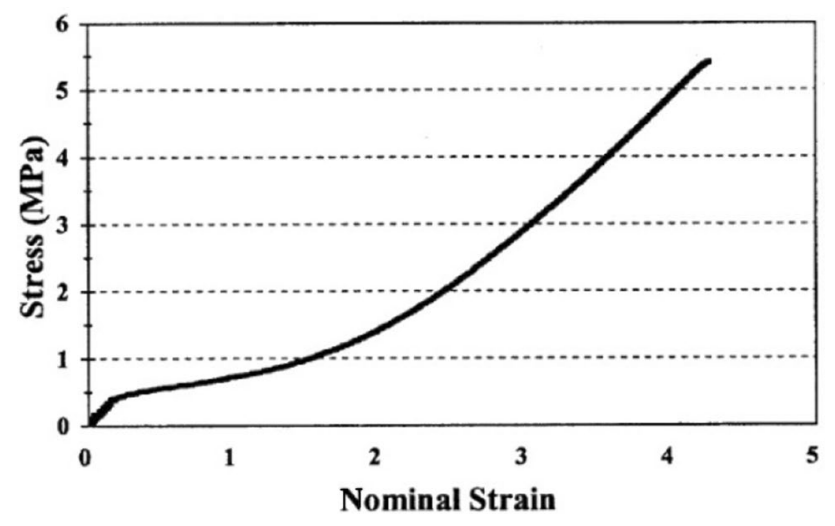

Fig. 4 Rubber's planar test (Yoo et al. 2002; Busfield and Muhr 2003; Tun Abdul Razak Research Centre 2002; Bradley et al. 2001)

Yeoh and polynomial $(N=2)$ which have estimated the original shear modulus below the real value, all other functions had a higher estimation than its true measure.

\section{Loading}

According to the experimental processes on the model, in the first step, a vertical load of $50 \mathrm{kN}$ was applied to the model uniformly distributed on top. In the second step, as the load exertion continues, a shear displacement of $60 \mathrm{~mm}$ was applied to the system. The amount strain due to this shear displacement was equal to $200 \%$.

\section{Meshing}

The Hex element shape was used for meshing the model in ABAQUS. C3D8H and C3D8R elements of the software were used to model rubber sheets and steel plates, respectively. The size of the meshes was assigned 4.5 units and the whole enmeshed elements were as many as 18,700 . The meshed HDRB and its deformation shape under shear strain are shown in Fig. 5.

\section{Solution method}

To analyze the finite elements model, the static general analysis was used; due to the high amount of displacement, the non-linear geometry was also activated.

\section{The analysis results}

After analyzing the models, the numerical hysteresis loops were attained which are shown in Figs. 6 and 7 along with the experimental hysteresis loop for comparison.
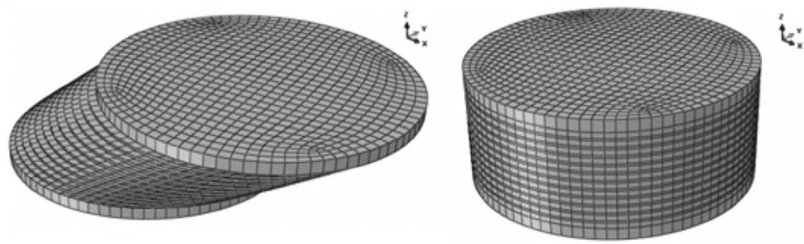

Fig. 5 HDRB model and its deformed shape
Table 4 Coefficients of the strain energy functions for the rubber in HDRBs
Table 5 Amount of error in calculating the model's initial shear modulus in comparison to the experimental value

\begin{tabular}{lllllll}
\hline Function & $C_{10}$ & $C_{01}$ & $C_{11}$ & $C_{20}$ & $C_{02}$ & $C_{30}$ \\
Mooney-Rivlin & 0.428550 & -0.068869 & - & - & - & - \\
Neo-Hookean & 0.232304 & - & - & - & - & - \\
Yeoh & 0.197738 & - & - & 0.002146 & - & 0.000091 \\
Polynomial $(N=2)$ & 0.195291 & -0.013261 & 0.000203 & 0.006484 & -0.000179 & - \\
Function & $\mu$ & $\lambda_{m}$ & $a$ & $\beta$ & - & - \\
van der Waals & 0.401558 & 4.381771 & 0.140441 & 0 & - & - \\
Arruda-Boyce & 0.393941 & 3.592024 & - & - & - & - \\
Function & $\alpha_{3}$ & $\alpha_{2}$ & $\alpha_{1}$ & $\mu_{3}$ & $\mu_{2}$ & $\mu_{1}$ \\
Ogden $(N=3)$ & 0.092292 & 4.024120 & 0.266487 & -2.827823 & 0.063751 & 3.212091 \\
\hline
\end{tabular}

\begin{tabular}{lllc}
\hline Function & $\begin{array}{l}\text { Model's shear modulus } \\
(\mathrm{MPa})\end{array}$ & $\begin{array}{l}\text { Experimental shear modulus } \\
(\text { Salomon et al. 1999) }(\mathrm{MPa})\end{array}$ & $\begin{array}{l}\text { Error percentage } \\
(\%)\end{array}$ \\
\hline Mooney-Rivlin & 0.72 & 0.40 & 80.00 \\
Neo-Hookean & 0.46 & 0.40 & 15.00 \\
Ogden $(N=3)$ & 0.45 & 0.40 & 12.50 \\
Yeoh & 0.40 & 0.40 & 0.00 \\
Arruda-Boyce & 0.41 & 0.40 & 2.50 \\
Polynomial $(N=2)$ & 0.38 & 0.40 & -5.00 \\
van der Waals & 0.40 & 0.40 & 0.00 \\
\hline
\end{tabular}


Fig. 6 Experimental and numerical hysteresis loops resulted from Mooney-Rivlin, polynomial $(N=2)$, van der Waals and Yeoh functions for HDRBs
Fig. 7 Experimental and numerical hysteresis loops resulted from neo-Hookean, Ogden $(N=3)$ and Arruda-Boyce functions for HDRBs
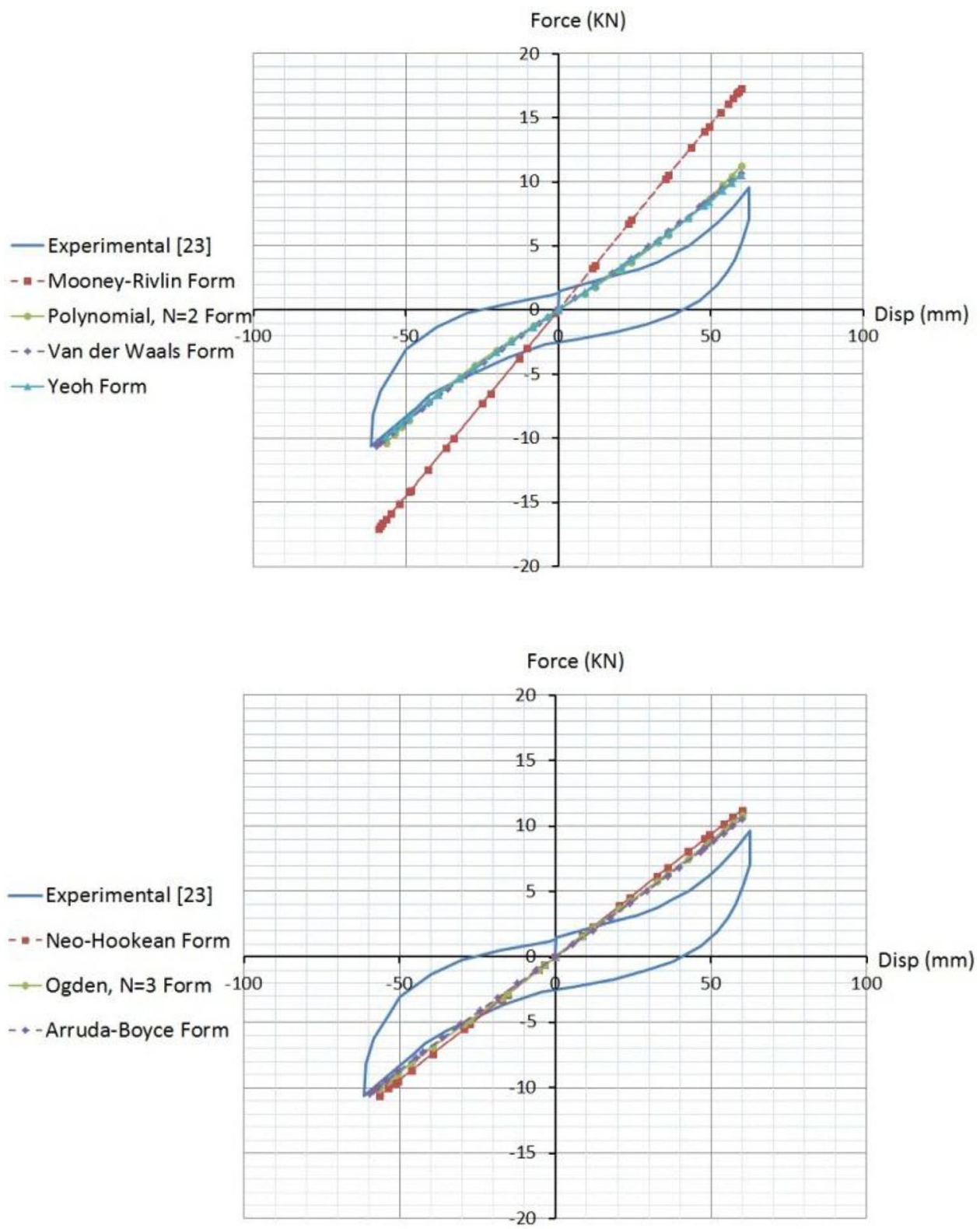

As seen in Figs. 6 and 7, in modeling HDRB the resulted hysteresis loop is linear. Therefore, the amount of energy damping in the isolating system cannot be measured. To determine the amount of error resulting from each hysteresis loop, the effective stiffness values of the models were calculated using Eq. (12) and compared to the experimental results in Table 6.

$K_{\mathrm{eff}}=\frac{F^{+}-F^{-}}{\Delta^{+}-\Delta^{-}}$

where $F^{+}$is the corresponding force with the maximum displacement, and $F^{-}$is the corresponding force with the minimum displacement.

What is concluded from the hysteresis loops and Table 6 is that the effective stiffness of the experimental model is generally less than that of the analytical models. The best result is for Yeoh function. Arruda-Boyce, van der Waals, and Ogden $(N=3)$ functions come next, respectively. These four functions have an error less than $10 \%$.

\section{Modeling the lead rubber bearings (LRB)}

For lead rubber bearings (LRBs), three samples were modeled. The first model was chosen from the study of Doudoumis et al. (2005). The second and third models were selected from the paper presented by Nersessyan et al. (2001). The interpretation of the modeling process and the results are shown in the following. 
Table 6 Comparing the calculated effective stiffness with the experimental results in HRDBs

\begin{tabular}{lcccccc}
\hline Samples & $F^{+}(\mathrm{KN})$ & $\Delta^{+}(\mathrm{mm})$ & $F^{-}(\mathrm{KN})$ & $\Delta^{-}(\mathrm{mm})$ & $K_{\text {eff }}(\mathrm{KN} / \mathrm{mm})$ & Error percentage \\
\hline Experimental & 9.770 & 63.151 & -10.712 & -61.766 & 0.164 & - \\
Mooney-Rivlin & 17.279 & 60.000 & -17.040 & -59.121 & 0.288 & $75.72 \%$ \\
Neo-Hookean & 11.199 & 60.000 & -10.594 & -56.625 & 0.187 & $13.98 \%$ \\
Ogden $(N=3)$ & 10.833 & 60.000 & -10.124 & -56.625 & 0.180 & $9.60 \%$ \\
Yeoh & 10.555 & 60.000 & -9.861 & -56.625 & 0.175 & $6.78 \%$ \\
Arruda-Boyce & 10.535 & 60.000 & -10.465 & -59.625 & 0.176 & $7.08 \%$ \\
Polynomial $(N=2)$ & 11.252 & 60.000 & -10.392 & -56.625 & 0.186 & $13.19 \%$ \\
van der Waals & 10.663 & 60.000 & -10.589 & -59.625 & 0.178 & $8.36 \%$ \\
\hline
\end{tabular}

\section{Geometry}

All three models are three-dimensional having the characteristics shown in Table 7.

\section{Defining material}

LRBs consist of three main materials: rubber, steel, and lead. Steel was defined according to Table 1 and lead according to Table 2. The rubber's properties are listed in Table 8.

Regarding the fact that there are not any experimental results for quadruple tests on rubber for determining the coefficients of the strain energy functions, the required tests were done by the finite element software itself. To do this, the software instructions state that there must be the results of at least two tests. Regarding the fact that rubber is usually considered incompressible, there is no need to do the volumetric test. In this study, the tests that have been done for rubber are the uniaxial and planar shear tests.
To do the uniaxial tension test, the rubber whose properties are presented in the standard DIN53504-S2 was used. The dimensions of the model are shown in Fig. 8 (Trevor 2001). The model's thickness is $2 \mathrm{~mm}$.

The sample was modeled two dimensionally and the rubber was defined using the Arruda-Boyce function. To use this function, the initial shear modulus and the amount of locking stretch $\left(\lambda_{m}\right)$ are needed. Regarding the amount of isolator's strain and the vast range of numerical tests, 3 seems the proper value for $\lambda_{m}$. This amount, which was determined by trial and error, was a premise that the speed and precision of the solution would be higher.

To analyze the model, the implicit dynamic analysis was used, and the model was considered as planar tension. Therefore, the CPS4R element was used for meshing. In Fig. 9, the created model of rubber as well as its deformed shape under uniaxial tension is presented.

After analyzing the model, the strain-stress curve for rubber in its central zone was attained.

Table 7 Geometrical specifications of the LRB models

\begin{tabular}{llll}
\hline Isolator characteristics & $\begin{array}{l}\text { First model (Imbimbo and De } \\
\text { Luca 1998) }\end{array}$ & $\begin{array}{l}\text { Second model (Bergstrom } \\
\text { 2002) }\end{array}$ & $\begin{array}{l}\text { Third model } \\
\text { (Bergstrom } \\
\text { 2002) }\end{array}$ \\
\hline Diameter of top and bottom loading plates (mm) & & 450 & 180 \\
Thickness of top and bottom loading plates (mm) & 601 & 23 & 15 \\
Diameter of top and bottom fixing plates (mm) & 31.8 & - & - \\
Thickness of top and bottom fixing plates (mm) & 431 & - & 180 \\
Diameter of rubber sheets (mm) & 25.4 & 450 & 3 \\
Thickness of rubber sheets (mm) & 431 & 4 & 21 \\
Number of rubber sheets & 9.5 & 44 & 180 \\
Diameter of steel plates (mm) & 11 & 450 & 1 \\
Thickness of steel plates (mm) & 431 & 3 & 20 \\
Number of steel plates & 3 & 43 & 25.4 \\
Diameter of lead core (mm) & 10 & 90 & 83 \\
Height of lead core (mm) & 116.8 & 305 & 7 \\
Lead core yield stress (MPa) & 185 & 6 \\
\hline
\end{tabular}


Table 8 Initial properties of rubber in the modeled LRBs

\begin{tabular}{llll}
\hline Rubber properties & $\begin{array}{l}\text { First model (Dou- } \\
\text { doumis et al. 2005) }\end{array}$ & $\begin{array}{l}\text { Second model } \\
\text { (Nersessyan et al. 2001) }\end{array}$ & $\begin{array}{l}\text { Third model } \\
\text { (Nersessyan et al. } \\
2001)\end{array}$ \\
\hline Initial shear modulus (MPa) & 0.62 & 0.59 & 0.59 \\
Initial bulk modulus (MPa) & 1500 & - & - \\
\hline
\end{tabular}

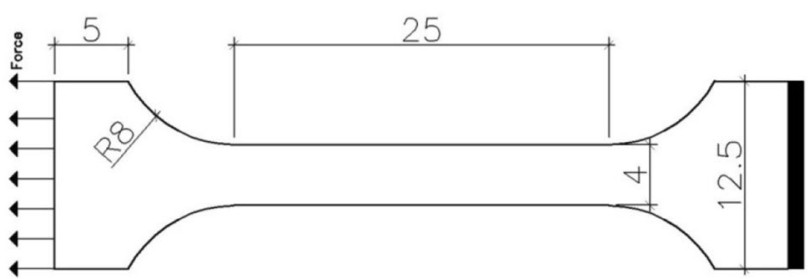

Fig. 8 Dimensions of the rubber model for uniaxial tension test (mm)

To do the planar shear test, a two-dimensional model for the rubber with the following measurements and a thickness of $2 \mathrm{~mm}$ was used (Forni et al. 2002) (Fig. 10).

All the stages of modeling and analysis of this model are the same as those of the rubber under uniaxial tension test. The meshed model and its deformed shape are shown in Fig. 11.

After attaining the stress-strain curves according to Fig. 12 the coefficients for strain energy functions were determined according to Table 9 for the first type of rubber in LRBs and Table 10 for second and third types.

After determining the coefficients of the strain energy functions, the initial shear modulus value was compared to the experimental value in order to calculate the amount of error in each function (Table 11).

For the first rubber model, the Arruda-Boyce function had the least error followed by the functions of Yeoh, Ogden $(N=3)$, neo-Hookean, Mooney-Rivlin, van der Waals and polynomial $(N=2)$, respectively. Other than the functions of Mooney-Rivlin and neo-Hookean, all other functions estimated the initial shear modulus below the real value.

For the second and third models of rubber, too, the Arruda-Boyce function had the least error. After that came the functions of Yeoh, van der Waals, Ogden $(N=3)$, polynomial $(N=2)$, neo-Hookean and Mooney-Rivlin. The functions of Mooney-Rivlin, neoHookean and Yeoh have estimated the initial value of the

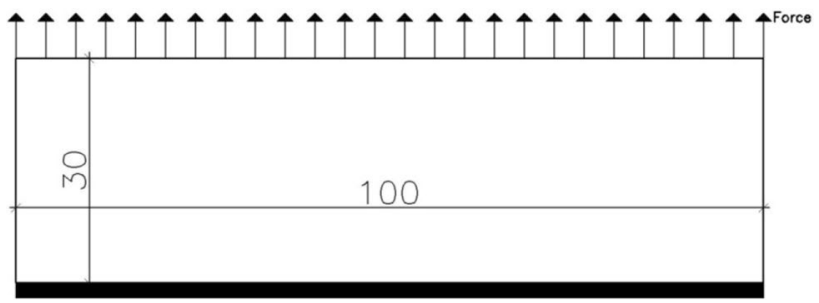

Fig. 10 Dimensions of the rubber model for the planar shear test (mm)

shear modulus higher than its real value, yet the other functions have reached a lower value than the real one.

\section{Loading}

To conduct the hysteresis cycle test, first the vertical load is applied to the model. Then, in the second stage, along with this load, the shear displacement is exerted on the isolating system. The amount of the vertical load and displacement applied to each of the three models of LRB is shown in Table 12.

\section{Meshing}

The Hex element shape was used for meshing the model in ABAQUS. C3D8H and C3D8R elements of the software were used to model rubber sheets and steel plates, respectively. All the meshed elements of the first model were equal to 6016 elements, the second model 30349 , and the third model 4945 . The meshed model of each LRB and its deformed shape caused by the shear displacement are presented in Figs. 13, 14 and 15.
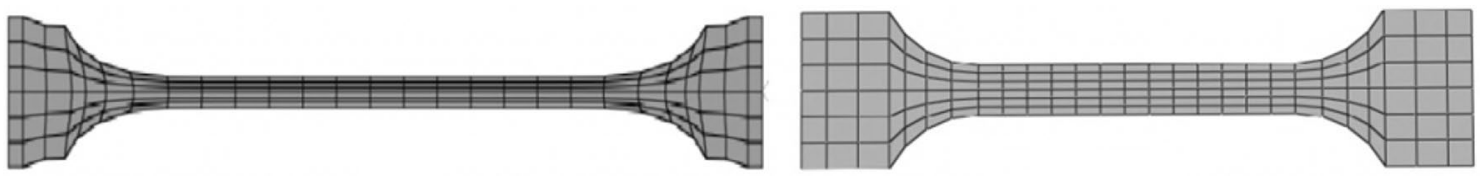

Fig. 9 Rubber model for uniaxial tension test and its deformed shape under tension force 

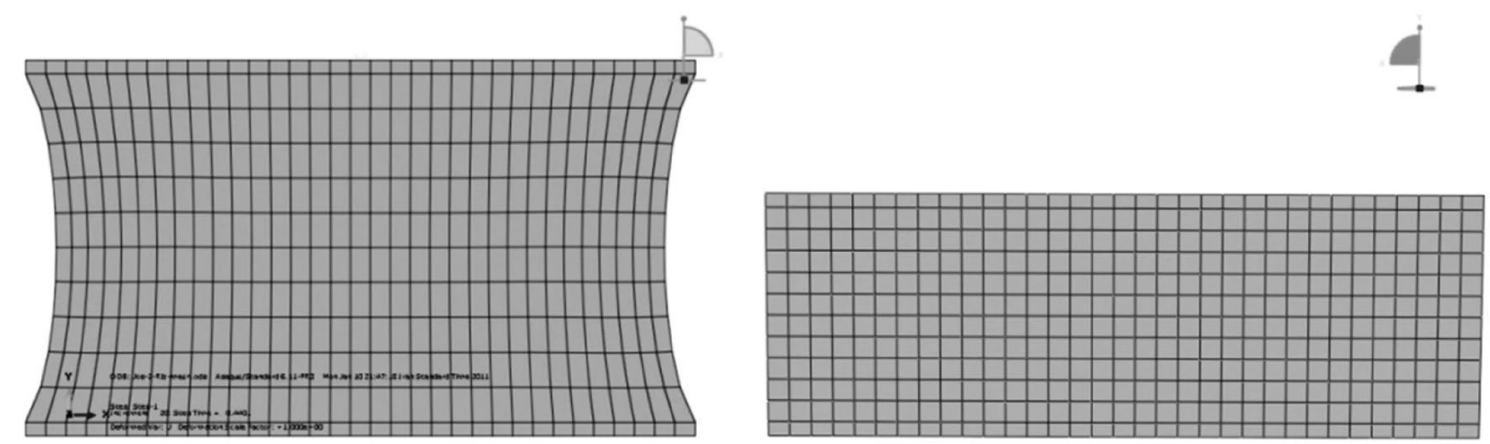

Fig. 11 Rubber model for the planar shear test and its deformed shape under tension force

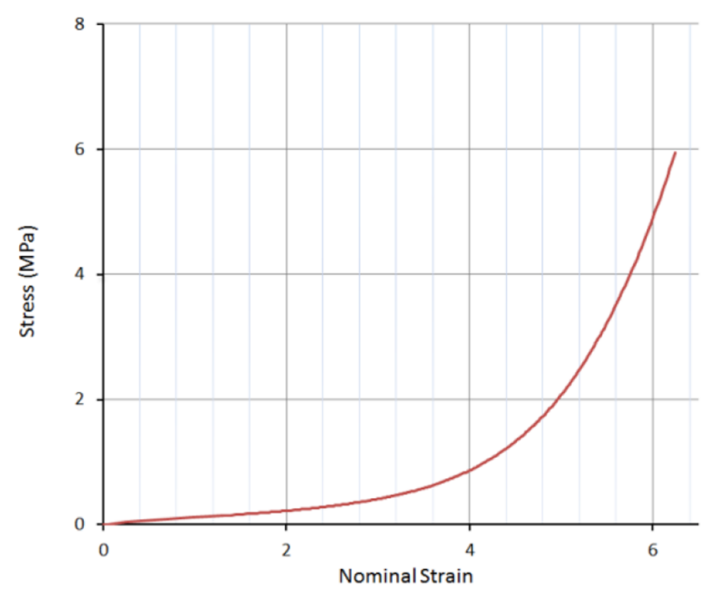

m1- uniaxial test

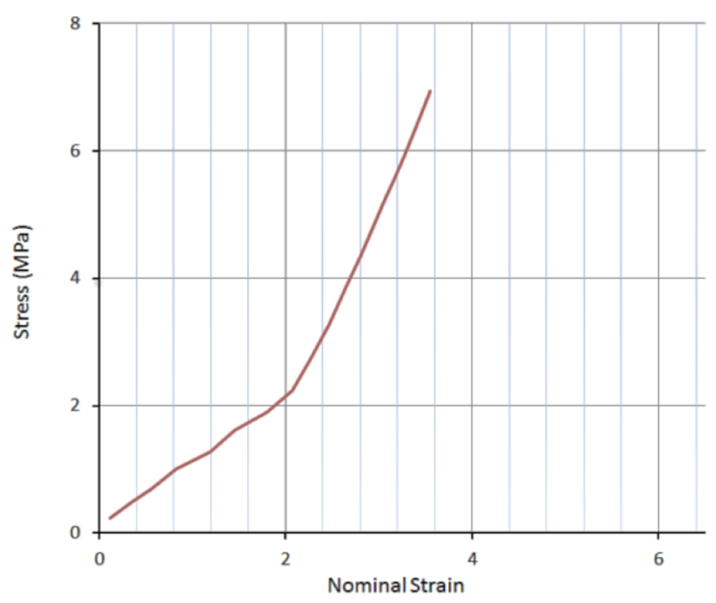

m1- planar test

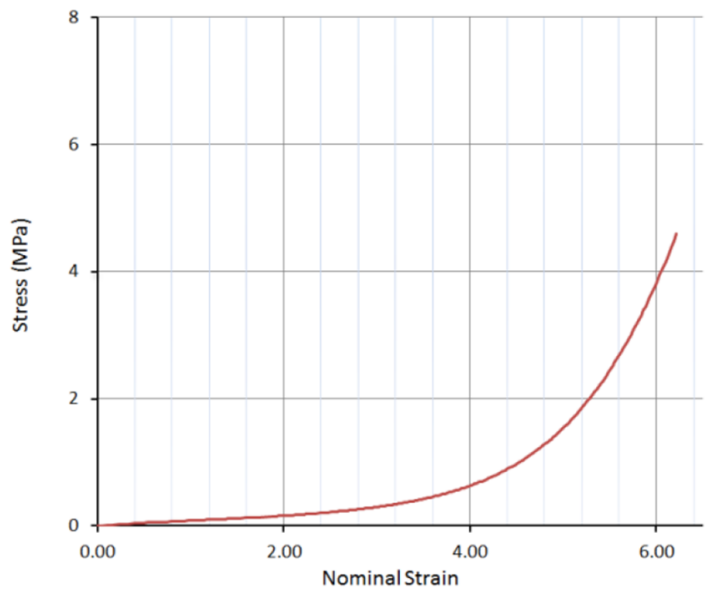

$\mathrm{m} 2,3-$ uniaxial test

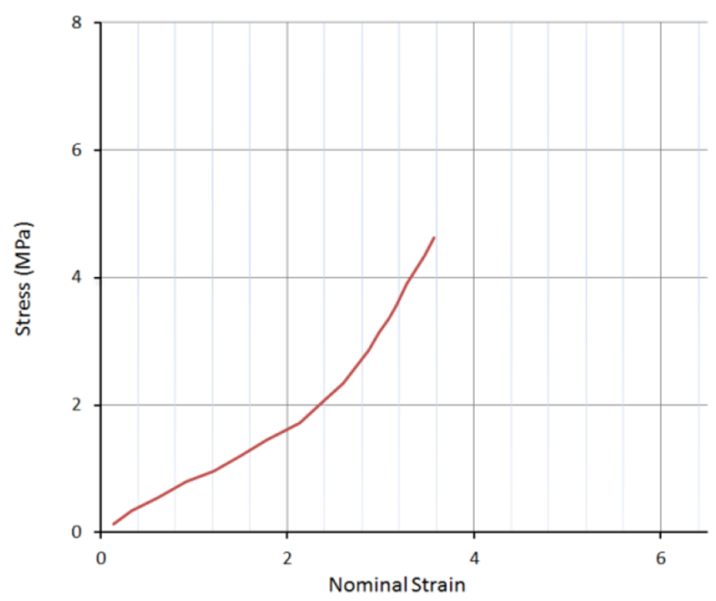

m2.3- planar test

Fig. 12 Stress-strain curves resulted from rubber's tests

\section{Analysis results}

In Figs. 16, 17, 18, 19, 20 and 21, the hysteresis loops of the strain energy functions are compared with the experimental results.

First model: 
Table 9 Coefficients of the strain energy functions for the first type of rubber in LRBs
Table 10 Coefficients of the strain energy functions for the second and third types of rubber in LRBs

\begin{tabular}{lllllll}
\hline Function & $C_{10}$ & $C_{01}$ & $C_{11}$ & $C_{20}$ & $C_{02}$ & $C_{30}$ \\
\hline Mooney-Rivlin & 0.053708 & -0.670950 & - & - & - & - \\
Neo-Hookean & 0.367465 & - & - & - & - & - \\
Yeoh & 0.287802 & - & - & 0.001890 & - & 0.000424 \\
Polynomial $N=2$ & 1.114475 & -0.912280 & -0.575830 & 0.1199180 & 0.470235 & - \\
\hline Function & $\mu$ & $\lambda_{m}$ & $a$ & $\beta$ & - & - \\
\hline van der Waals & 0.454676 & 7.637174 & -0.150100 & 0.000000 & - & - \\
Arruda-Boyce & 0.569053 & 3.039270 & - & - & - & - \\
\hline Function & $\alpha_{3}$ & $\alpha_{2}$ & $\alpha_{1}$ & $\mu_{3}$ & $\mu_{2}$ & $\mu_{1}$ \\
\hline Ogden $N=3$ & -7.200500 & 7.747580 & 2.476592 & 0.00359 & 0.000318 & 0.517097 \\
\hline
\end{tabular}

\begin{tabular}{lllllll}
\hline Function & $C_{10}$ & $C_{01}$ & $C_{11}$ & $C_{20}$ & $C_{02}$ & $C_{30}$ \\
\hline Mooney-Rivlin & 1.636999 & -1.190500 & - & - & - & - \\
Neo-Hookean & 0.410013 & - & - & - & - & - \\
Yeoh & 0.311112 & - & - & -0.004411 & - & 0.000580 \\
Polynomial $N=2$ & 1.684135 & -0.527640 & -0.866020 & 0.167200 & 0.713158 & - \\
\hline Function & $\mu$ & $\lambda_{m}$ & $a$ & $\beta$ & - & - \\
\hline van der Waals & 0.532218 & 7.586497 & 0.009330 & 0.000000 & - & - \\
Arruda-Boyce & 0.546603 & 2.976734 & - & - & - & - \\
\hline Function & $\alpha_{3}$ & $\alpha_{2}$ & $\alpha_{1}$ & $\mu_{3}$ & $\mu_{2}$ & $\mu_{1}$ \\
\hline Ogden $N=3$ & -8.304410 & 8.322200 & 2.390980 & 0.000063 & 0.000134 & 0.527638 \\
\hline
\end{tabular}

Table 11 Amount of error in calculating the initial shear modulus of the numerical models using the functions in comparison to the experimental value in LRBs

\begin{tabular}{llllr}
\hline Function & Rubber type & $\begin{array}{l}\text { Model's shear modu- } \\
\text { lus (MPa) }\end{array}$ & $\begin{array}{l}\text { Experimental shear modulus (MPa) (Martelli } \\
\text { et al. 1992; Garcia et al. 2005) }\end{array}$ & $\begin{array}{l}\text { Error } \\
\text { percentage } \\
(\%)\end{array}$ \\
\hline Mooney-Rivlin & First model & 0.77 & 0.62 & 24.19 \\
& Second and third model & 0.89 & 0.59 & 50.85 \\
Neo-Hookean & First model & 0.73 & 0.62 & 17.74 \\
& Second and third model & 0.82 & 0.59 \\
Ogden $N=3$ & First model & 0.52 & 0.62 & 38.98 \\
& Second and third model & 0.53 & 0.59 & -16.13 \\
Yeoh & First model & 0.58 & 0.62 & -10.17 \\
& Second and third model & 0.62 & 0.59 & -6.45 \\
Arruda-Boyce & First model & 0.61 & 0.62 & -1.08 \\
& Second and third model & 0.59 & 0.59 & -1.61 \\
Polynomial $N=2$ & First model & 0.40 & 0.62 & -35.00 \\
& Second and third model & 0.31 & 0.59 & -47.46 \\
van der Waals & First model & 0.45 & 0.62 & -27.42 \\
& Second and third model & 0.53 & 0.59 & -10.17 \\
\hline
\end{tabular}

The second model:

The third model:

In these hysteresis loops, the models' behaviors have been illustrated qualitatively. After calculating the effective stiffness and the effective damping for each hysteresis loop, their quantitative errors are determined. The value of the effective stiffness and the effective damping can be determined using 
Table 12 Vertical load and displacement applied to the LRB models
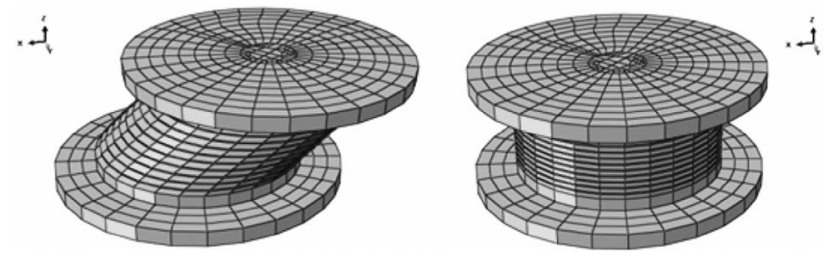

Fig. 13 First LRB model and its deformed shape
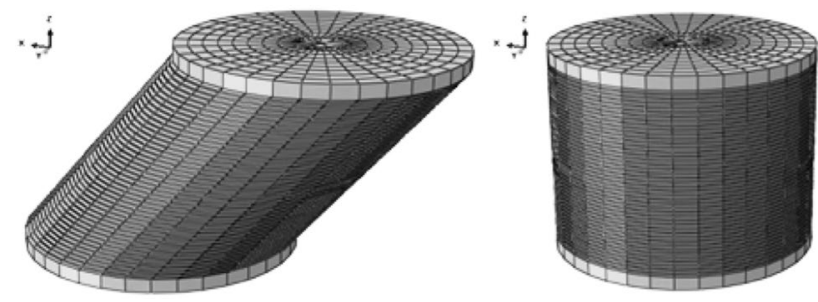

Fig. 14 Second LRB model and its deformed shape

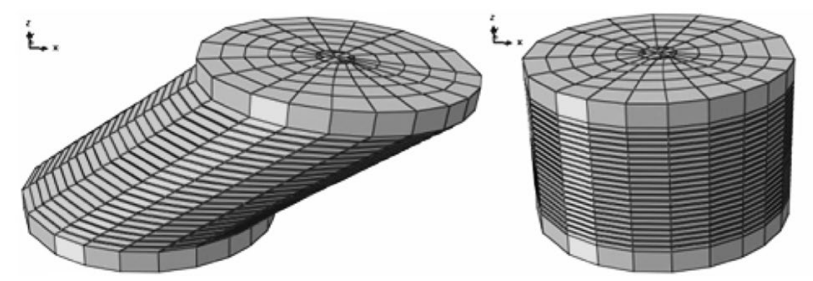

Fig. 15 Third LRB model and its deformed shape

Eq. (12) which was presented before and Eq. (13) which is shown below.

$\beta_{\text {eff }}=\left(\frac{2}{\pi}\right)\left[\frac{E_{\text {loop }}}{K_{\text {eff }}\left(\left|\Delta^{+}\right|+\left|\Delta^{-}\right|\right)^{2}}\right]$,

where $\Delta^{+}$is the maximum shear displacement in the isolating system, and $\Delta^{-}$is the minimum displacement (maximum shear displacement in the opposite direction). The effective stiffness $\left(K_{\text {eff }}\right)$ should be calculated for displacements $\Delta^{+}$and $\Delta^{-}$. $\beta_{\text {eff }}$ is the effective damping and $E_{\text {loop }}$ is the absorbed energy in each loading cycle which is obtained through calculating the inner area of the curve. The two above-mentioned parameters for all three LRBs are presented in Table 13.

In the first model with the shape factor of 11.3 and shear strain of $100 \%$, the best performance belongs to the polynomial $(N=2)$ function with error of $6 \%$. After that, the functions of Yeoh, Ogden models $(N=3)$, van der Waals and Arruda-Boyce with a nearly similar performance vary in error from 11 to $14 \%$, respectively. The neo-Hookean and Mooney-Rivlin functions were the weakest with errors equal to $18 \%$ and $20 \%$, respectively.

In the second model, the shape factor of the isolating system is 28.1 and the applied shear strain is $150 \%$. Here too, the polynomial $(N=2)$ and an error less than $3 \%$ had the best performance followed by Yeoh and $\operatorname{Ogden}(N=3)$ with $23 \%$ error. The Arruda-Boyce and van der Waals functions with $27 \%$ and $31 \%$ errors, respectively, come next. The neoHookean and Mooney-Rivlin functions have had the worst performances.

In the third model, the shape factor of the rubber layers is equal to 15 and its shear strain compared to the other two models is much higher (shear strain equals to $300 \%$ ). Here too, the minimum error belongs to polynomial $(N=2)$ function which shows a 30\% discrepancy in estimating the effective stiffness. The Yeoh function with $41 \%$ error comes next. After that, Ogden $(N=3)$, Arruda-Boyce, van der Waals, neo-Hookean and Mooney-Rivlin have the highest errors, respectively.

As seen, among the studied functions, the polynomial $(N=2)$ has the best performance.

These functions have the same ranking in estimating effective damping as they did in estimating effective stiffness of the isolators. The calculated effective damping values for all the functions as well as the amount of their errors are shown in Table 14, in order of the error percentages.

In the first model, the polynomial function has an error about $-1.6 \%$, and Yeoh, Ogden $(N=3)$, van der Waals and Arruda-Boyce with a similar performance have an error equal to $-6 \%$ to $-10 \%$. The neo-Hookean and Mooney-Rivlin functions are the weakest in estimating the effective damping.

In the second model, too, the polynomial $(N=2)$ function and $18 \%$ error had the best estimation. After that come the Yeoh, Ogden $(N=3)$, Arruda-Boyce and van der Waals. Then, the neo-Hookean and Mooney-Rivlin 
Fig. 16 Experimental and numerical hysteresis loops resulted from Mooney-Rivlin, polynomial $(N=2)$, van der Waals and Ogden $(N=3)$ functions for the first type of rubber in LRBs
Fig. 17 Experimental and numerical hysteresis loops resulted from Neo-Hookean, Arruda-Boyce and Yeoh functions for the first type of rubber in LRBs
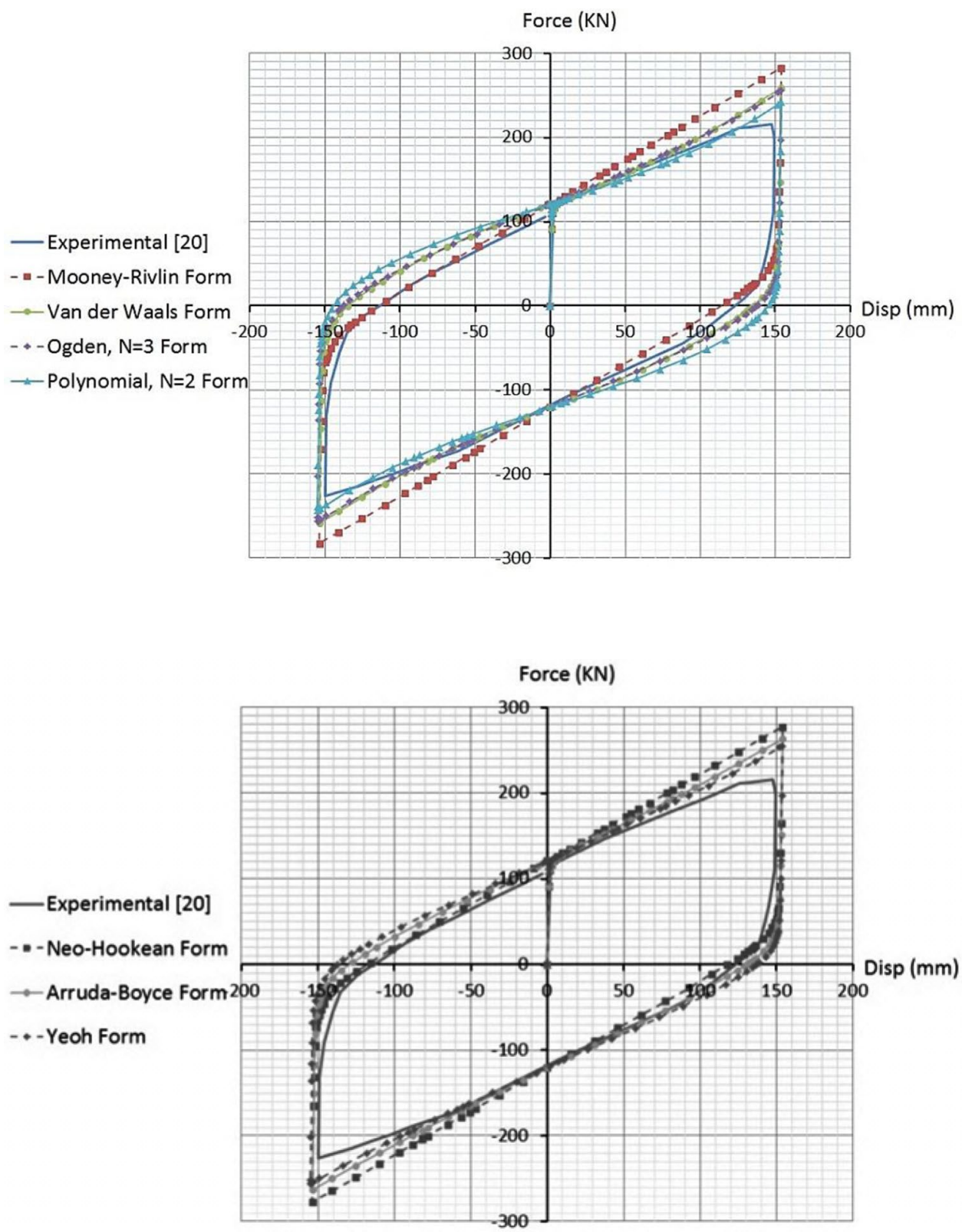

with $-45 \%$ and $-49 \%$ have the highest error values, respectively.

The effective damping of the third model is less than the other models. Here too, the polynomial $(N=2)$ function and an error below $2 \%$ had the best result. Yeoh, Ogden $(N=3)$, Arruda-Boyce, van der Waals, neoHookean and Mooney-Rivlin come, respectively, after that.

\section{Conclusion}

- High damping rubber bearing (HDRB)
Based on the available results of experimental tests conducted on the rubber of the isolators by other researchers and obtaining the stress-strain curve of each, the coefficients of the strain energy functions were derived. In Yeoh and van der Waals functions which estimated the shear modulus of the rubber without any error, the isolating system, too, had better results. Regarding these considerations, the best function is the Yeoh or the reduced polynomial function $(N=2)$ whose error in estimating the effective stiffness is below $7 \%$.

The major errors in analyzing the HDRB models for obtaining the hysteresis loops are due to two factors: 
Fig. 18 Experimental and numerical hysteresis loops resulted from Mooney-Rivlin, polynomial $(N=2)$, van der Waals and Ogden $(N=3)$ functions for the second type of rubber in LRBs
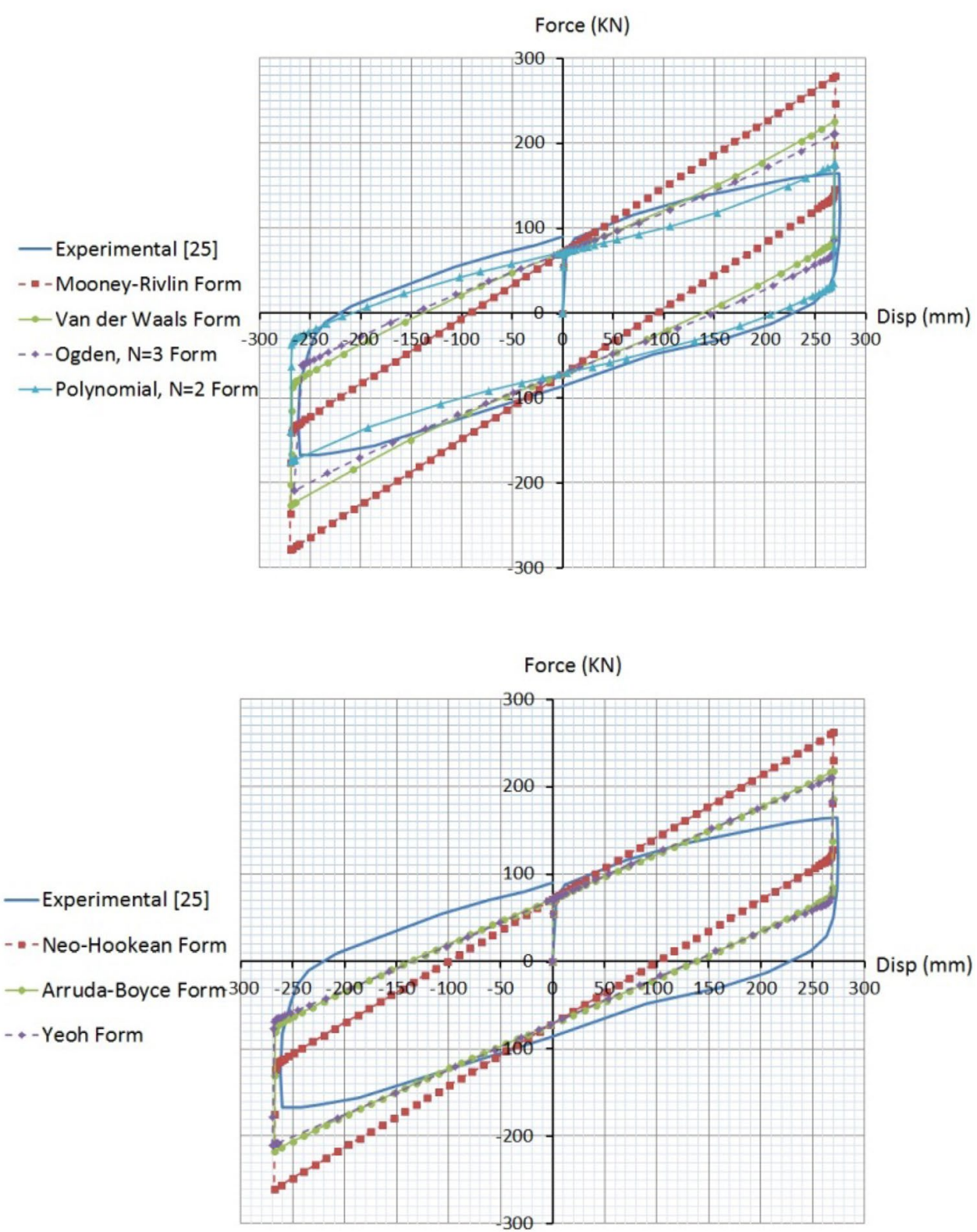

Fig. 19 Experimental and numerical hysteresis loops resulted from neo-Hookean, Arruda-Boyce and Yeoh functions for the second type of rubber in LRBs (a) It is the property of hyperelastic materials that their force-displacement behavior is completely reversible, and regarding the fact that there is no plasticity in HDRBs, the derived hysteresis loop will be in the form of a line. Therefore, the amount of energy in each cycle and the damping cannot be determined.

(b) The behavior of HDRBs is highly non-linear and the force-displacement behavior of the isolating system gains a softening attribute as the strain increases. As a result, in high strains the isolator's behavior cannot be modeled in all stages of loading exactly like what happens during experimental tests.

- Lead rubber bearings (LRB)
In the studied finite elements models, there were two types of error for LRBs: one caused by modeling the rubber tests which creates an error in determining the coefficients of the strain energy functions and another caused by modeling of LRBs.

In experimental models of LRBs, the stiffness and therefore the slope of the force-displacement curve decreases as the strain increases. However, in numerical modeling, the curve shows a linear behavior, therefore the error of modeling increases with the increase in strain. It seems the lower error in polynomial $(N=2)$ function is due to the lower value in the initial estimation for rubber's shear modulus.

The hysteresis loop of the LRBs is bilinear. The initial slope follows the elasticity modulus of lead. The yield 
Fig. 20 Experimental and numerical hysteresis loops resulted from Mooney-Rivlin, polynomial $(N=2)$, van der Waals and Ogden $(N=3)$ functions for the third type of rubber in LRBs

Fig. 21 Experimental and numerical hysteresis loops resulted from neo-Hookean, Arruda-Boyce and Yeoh functions for the third type of rubber in LRBs
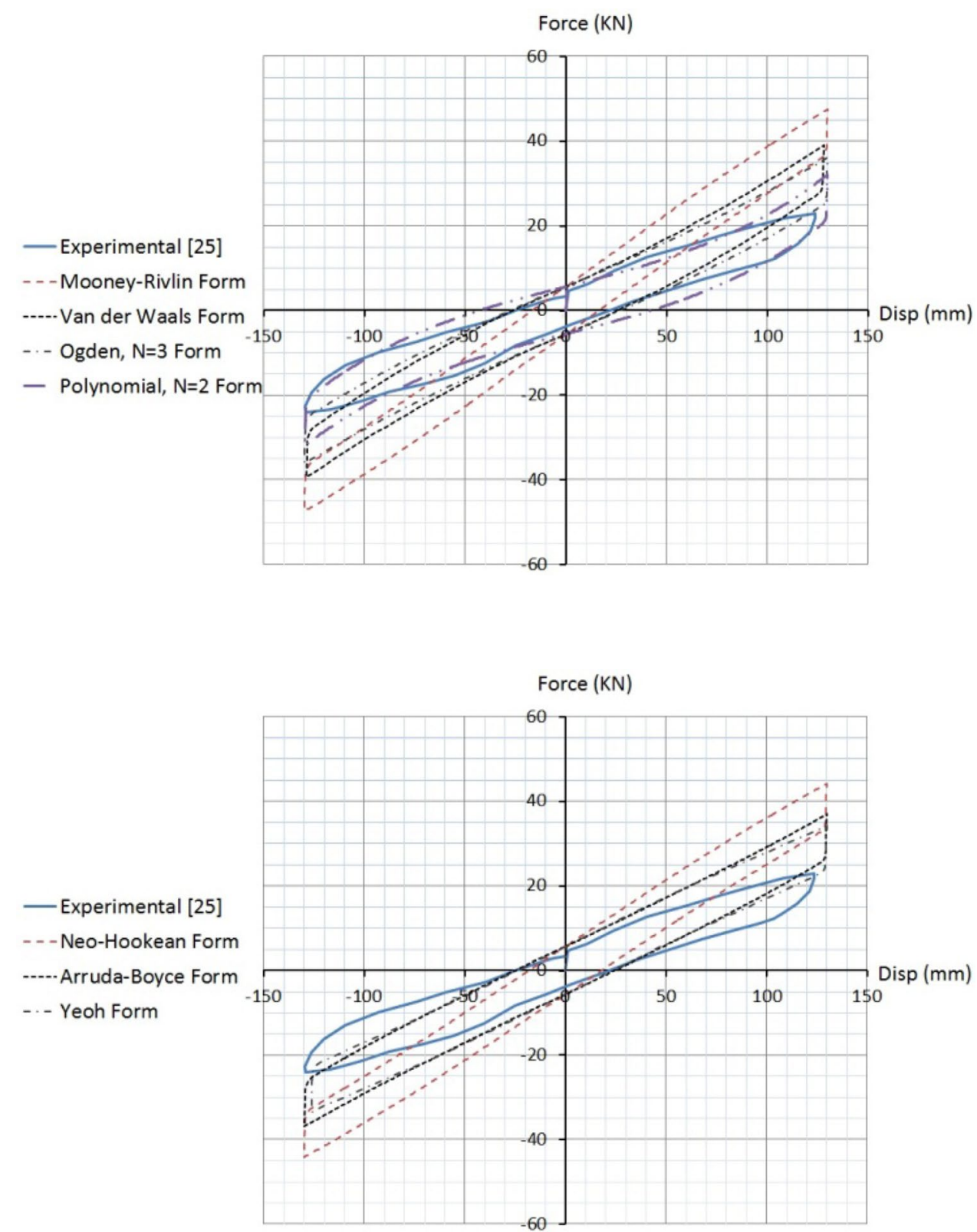

Table 13 Calculated effective stiffness of the LRB models and the amount of its error compared with the experimental results in order of error percentage

\begin{tabular}{|c|c|c|c|c|c|c|}
\hline \multirow[t]{2}{*}{ Sample } & \multicolumn{2}{|l|}{ First model } & \multicolumn{2}{|l|}{ Second model } & \multicolumn{2}{|l|}{ Third model } \\
\hline & $K_{\mathrm{eff}}(\mathrm{KN} / \mathrm{mm})$ & Error percentage & $K_{\mathrm{eff}}(\mathrm{KN} / \mathrm{mm})$ & Error percentage & $K_{\mathrm{eff}}(\mathrm{KN} / \mathrm{mm})$ & Error percentage \\
\hline Experimental & 1.474 & - & 0.636 & - & 0.187 & - \\
\hline Mooney-Rivlin & 1.838 & $19.80 \%$ & 1.034 & $62.58 \%$ & 0.367 & $95.52 \%$ \\
\hline Neo-Hookean & 1.802 & $18.20 \%$ & 0.972 & $52.83 \%$ & 0.341 & $81.73 \%$ \\
\hline van der Waals & 1.683 & $12.42 \%$ & 0.839 & $31.92 \%$ & 0.305 & $62.75 \%$ \\
\hline Arruda-Boyce & 1.711 & $13.85 \%$ & 0.808 & $27.04 \%$ & 0.284 & $51.67 \%$ \\
\hline Ogden $(N=3)$ & 1.658 & $11.10 \%$ & 0.784 & $23.27 \%$ & 0.278 & $48.06 \%$ \\
\hline Yeoh & 1.655 & $10.94 \%$ & 0.782 & $22.96 \%$ & 0.265 & $41.37 \%$ \\
\hline Polynomial $(N=2)$ & 1.570 & $6.11 \%$ & 0.650 & $2.20 \%$ & 0.245 & $30.58 \%$ \\
\hline
\end{tabular}


Table 14 Calculated effective damping of the LRB models and the amount of its error compared with the experimental results in order of error percentage

\begin{tabular}{|c|c|c|c|c|c|c|}
\hline \multirow[t]{2}{*}{ Sample } & \multicolumn{2}{|c|}{ First model } & \multicolumn{2}{|c|}{ Second model } & \multicolumn{2}{|c|}{ Third model } \\
\hline & $\beta_{\text {eff }}$ & Error percentage & $\beta_{\text {eff }}$ & Error percentage & $\beta_{\text {eff }}$ & Error percentage \\
\hline Experimental & 0.319 & - & 0.318 & - & 0.11 & - \\
\hline Mooney-Rivlin & 0.268 & $-15.99 \%$ & 0.162 & $-49.06 \%$ & 0.076 & $-31.03 \%$ \\
\hline Neo-Hookean & 0.273 & $-14.42 \%$ & 0.173 & $-45.60 \%$ & 0.081 & $-26.05 \%$ \\
\hline van der Waals & 0.293 & $-8.15 \%$ & 0.200 & $-37.11 \%$ & 0.090 & $-18.02 \%$ \\
\hline Arruda-Boyce & 0.288 & $-9.72 \%$ & 0.208 & $-34.59 \%$ & 0.097 & $-11.76 \%$ \\
\hline $\operatorname{Ogden}(N=3)$ & 0.297 & $-6.90 \%$ & 0.214 & $-32.70 \%$ & 0.099 & $-9.65 \%$ \\
\hline Yeoh & 0.298 & $-6.58 \%$ & 0.215 & $-32.39 \%$ & 0.105 & $-4.22 \%$ \\
\hline Polynomial $(N=2)$ & 0.314 & $-1.57 \%$ & 0.258 & $-18.87 \%$ & 0.112 & $1.97 \%$ \\
\hline
\end{tabular}

stress of lead indicates the ultimate strength in initial stiffness. The secondary stiffness is a function of the rubber's stiffness in a way that the secondary stiffness is higher for higher stiffness of rubber which is derived from the strain energy function.

Regarding the fact that lead core has an elastoplastic behavior during the horizontal loading process, the damping of the isolating system can be determined.

In modeling LRBs, the best result is attained from the polynomial $(N=2)$ function. The effective stiffness of the isolating system can be estimated with an error less than $3 \%$ at $150 \%$ shear strain and with the shape factor of 28.1 .

Open Access This article is distributed under the terms of the Creative Commons Attribution 4.0 International License (http://creativeco mmons.org/licenses/by/4.0/), which permits unrestricted use, distribution, and reproduction in any medium, provided you give appropriate credit to the original author(s) and the source, provide a link to the Creative Commons license, and indicate if changes were made.

\section{References}

APASmith M (2007) ABAQUS/Standard user's manual, version 6.7. Simulia, Providence, RI

Asl MJ, Rahman MM, Karbakhsh A (2014) Numerical analysis of seismic elastomeric isolation bearing in the base-isolated buildings. Open J Earthq Res 3:1-4

Bergstrom JS (2002) Determination of material parameters for the 8-chain model for use with ABAQUS, LS-DYNA and ANSYS. https://polymerfem.com/polymer_files/eightChain_findProper ties.pdf

Bradley GL, Chang PC, McKenna GB (2001) Rubber modeling using uniaxial test data. J Appl Polym Sci 81(4):837-848

Busfield JJC, Muhr AH (2003) Constitutive models for rubber. In: Proceeding of third European conference on constitutive models for rubber, 15-17 September, London, UK

Charlton DJ, Yang J, Teh KK (1993) A review of methods to characterize rubber elastic behavior for use in finite element analysis. In: Department of Mechanical Engineering, Curtin University of Technology, Perth, Western Australian, vol 67, pp 481-503

Doudoumis IN, Gravalas F, Doudoumis NI (2005) Analytical modeling of elastomeric lead-rubber bearings with the use of finite element micro models. In: 5th GRACM international congress on computational mechanics, Limassol

Forni M, La Grotteria M, Martelli A (2002) Verification and improvement of analytical modeling of seismic isolation bearings and isolated structures. In: Verification of analysis methods for predicting the behaviour of seismically isolated nuclear structures, final report of a coordinated research project, IAEATECDOC-1288, pp 105-130

Garcia R, Manuel J, Ruiz S, Oscar E, Lopez C (2005) Technical report hyperelastic material modeling. In: Departamento de Ingenier'ia Mec'anica, Universidad EAFIT

Guo Z, Sluys J (2008) Constitutive modelling of hyperelastic rubberlike materials. HERON 53(3):109-132

Imbimbo M, De Luca A (1998) FE stress analysis of rubber bearings under axial loads. Comput Struct 68:31-39

Martelli A, Indirli M, Spadoni B (1992) Experimental on seismic isolation bearings. In: Earthquake engineering tenth world conference, Rotterdam, pp 2385-2390

Mishra HK, Igarashi A, Matsushima H (2013) Finite element analysis and experimental verification of the scrap tire rubber pad isolator. Bull Earthq Eng 11:687-707

Mori A, Moss PJ, Carr AJ (1996) The seismic behavior of elastomeric and lead-rubber bearings. In: Elsevier science Ltd, eleventh world conference on earthquake engineering, paper no. 1692

Naeim F, Kelly JM (1999) Design of seismic isolated structures from theory to practice. Wiley, New York

Nersessyan T, Hovhannisyan G, Tonoyan A (2001) Investigations on stiffness-damping interaction for rubber bearings. J Struct Control 8(2):219-233

Ohsaki M, Miyamura T, Kohiyama M, Yamashita T, Yamamoto M, Nakamura N (2015) Finite-element analysis of laminated rubber bearing of building frame under seismic excitation. Earthq Eng Struct Dyn 4:1881-1898

Salomon O, Oller S, Barbat A (1999) Finite element analysis of base isolated buildings subjected to earthquake loads. Int J Numer Methods Eng 46:1741-1761

Suhara J, Takeda M, Tamura T (1992) Dynamic ultimate analysis of base-isolated system. In: Earthquake engineering tenth world conference, Rotterdam, pp 2395-2400

Talaeitaba SB, Pourmasoud MM, Jabbari M (2019) An innovative base isolator with steel rings and a rubber core. Asian J Civ Eng 20(3):313-325

Trevor EK (2001) Base isolation of structure. Holmes Consulting Group Ltd, Wellington

Tun Abdul Razak Research Centre (2002) Analysis methods for predicting the behaviour of isolators and formulation of simplified models for use in predicting response of structures to earthquake type input. In: Verification of analysis methods for 
predicting the behaviour of seismically isolated nuclear structures, final report of a coordinated research project, IAEA-TECDOC-1288, pp 29-78

Venkatesh K, Srinivasa Murthy PL (2012) Experimental validation and data acquisition for hyper elastic material models in finite element analysis. Int J Mech Ind Eng (IJMIE) 2(4):72-76

Yoo B, Lee JH, Koo GH (2002) Development of analysis methods for seismically isolated nuclear structures. In: Verification of analysis methods for predicting the behaviour of seismically isolated nuclear structures, Final report of a coordinated research project, IAEA-TECDOC-1288, pp 167-190

Publisher's Note Springer Nature remains neutral with regard to jurisdictional claims in published maps and institutional affiliations. 